\title{
Effects of Emotional Exhaustion on Employee Performance among Academic Staff of Tertiary Institutions in Ekiti State, Nigeria
}

\author{
${ }^{1}$ Akeke, Niyi Israel (Ph.D), ${ }^{1}$ Ogundipe Christie Folake (Ph.D), ${ }^{1}$ Bankole Oluwole Adeniyi \& ${ }^{2}$ Alamu \\ Ibunkunoluwa Oluwafunmilayo
}

${ }^{1}$ Department of Business Administration

Ekiti State University, Ado-Ekiti, Nigeria

${ }^{2}$ Federal University, Oye-Ekiti, Ekiti State, Nigeria

\begin{abstract}
The study examined the effects of emotional exhaustion on employee performance among academic staff of tertiary institutions in Ekiti State, Nigeria. A descriptive survey research design was adopted for the study. The population of the study comprised 2609 academic staff of tertiary institutions in Ekiti State. The sample size of 1214 respondents was employed and it was determined by the Yamani sampling model. Data used for the study were gathered through the structured questionnaire. Data gathered were analyzed using multiple regression. The result showed that time constraint has a significant effect on employee performance. Both work pressure and physical ailment has a negative effect on employee performance $(t=3.454, t=-2.776$ and $t=-2.910$, $p<0.05)$. The study concluded that emotional exhaustion is significantly related to employee performance among academic staff of tertiary institutions in Ekiti State, Nigeria.
\end{abstract}

Keyword: Emotional Exhaustion, Employee, Performance.

\section{INTRODUCTION}

Recently, studies on job burnout and job stress are being performed in the field of organizational behaviour. Therefore, Job burnout remains a mental phenomenon, which is a form of persistent stress reactions arising from accumulated and long-term negative effects of job stress. Job burnout mostly occur among employees who engage in professional personal services such as, teacher, doctor, nurse, lawyer, social worker, police and fire public official. The rapidity with which the concept of job burnout has been integrated into everyone's life is beyond belief. During the two decades, employees had experienced job stress and because of the constant job stress, they have fallen into job burnout. As a result, structure members experience mental insecurity and job stress on their responsibilities constantly. Structure members experiencing extreme job stress are in an emotional exhausted situation because of overload of task, ambiguous of role and role conflict (Kwag \& Kim, 2009).In the same vein, Basami, Chizari and Abbasi (2013) asserted that burnout is a problem for people who work in human service professions. However, burnout is a predicament that affects not only the person experiencing it but the co-workers and the organization in which the person is employed. The burnout individual soon troubles many of their co-workers with this problem. However, burnout disturbs first the individual's balance and then the organizational balance, disrupting efficiency and productivity and tothis end, effectiveness; thus, instantidentification of this phenomenon and its indicators is of enormously importance in avoiding its occurrence.

Employee job performance has always been a major challenge in organizational management and adopting effective ways to motivate employees to achieve higher job performance as well as increasing organizational competitiveness which is the main objective of every business organisation (Inuwa, 2016). Ogbulafor, (2011) is of the opinion that the deteriorating level employee performance in Nigerian tertiary institutions is fast becoming a serious threat to survival of universities in Nigeria which needs to be deal with urgently. Therefore, it is believed that employee performance is influential to organisational growth and performance. The employees are regarded as the major business resources that ease the daily activities and operations of an organisation (Mudah, Rafiki\&harahap, 2014). Similarly, Oluwafemi (2010) asserted that organisational effectiveness and efficiency depends on how effective and efficient the employees in the organization are. Employer's ability to understand employee's satisfaction in relation to schedules and daily responsibilities will impact greatly on employee productivity and performance (Inuwa, 2016). 
Most organizations with the aim of attaining higher productivity end up saddling employees with overload of work in order to meet deadline and this might have psychological and physical effects on the employees which may result in something contrary to what these organizations intend accomplishing. Although organizations are more particular than in the past to the implications of the trauma their employees experience when astonishing demands are placed on them (Roloff\& Brown, 2011). In view of the above, previous researchers dwell much on emotional exhaustion as a dimension of burnout on different variables, researchers like Akhighe and Gail (2017) in Nigeria, Bavani, Abdullah and Manif (2016) in Malaysia and Boonratana and Gharleghi (2015) in Malaysia to mention but few. However, there is controversy in the study of the aforementioned studies in Malaysia that not all the three variables (Depersonalisation, emotional exhaust and personal accomplishment) employed as a proxy of job burnout were found significant in Malaysia. Base on this premise, the only emotional exhaustion will be revalidated in Ekiti State Tertiary Institution particularly among academic staff. Therefore, this study will be of benefit to tertiary institution management and staff on the need to put a good structure in place to motivate employees and to reduce borne out and finally, this study shall contribute to the existing literature in the field of human resources management.

\section{LITERATURE REVIEW}

\subsection{Emotional Exhaustion}

Emotional exhaustion is the first component of job burnout which is characterized by a lack of energy and a feeling that one's emotional resources are expended. This "compassion fatigue" may coexist with feelings of frustration and tension as workers realize they can nolonger cope with or be as responsible for clients as they have been doing previous time. A common symptom is anxiety at the view of returning to work for another day. Emotional exhaustion arises when there is devastating demand on one's time and energy. Emotional exhaustion is known as a core dimension of burnout (Gaines \&Jermier, 1983) as well as a situation caused by psychological and emotional demands expected of the employees. Since emotional exhaustion is conceptualised as the first stage of burnout (Maslach\& Jackson, 1981), emotional exhaustion is essential as it is a point of possible managerial interference in the burnout process. Maslach and Jackson (1986) identified emotional exhaustion as the most vital aspect among the dimension of job burnout.

Employees who encounters emotional exhaustion feels overextended and overworked, where one fears coming to work and faces lack of energy to face another day at the job (Maslach\&Leiter, 1997). In this condition, frustration and hopelessness dominate as the demand of the job continues to outperform the employee's competence (Pines \& Aronson, 1988).According to Cropanzano, Rupp and Byrne (2003) and Westman and Eden (1997), emotional exhaustion is one of the major factors that discourage employees from continuing with an organisation. Emotional exhaustion is consistently positively related to turnover intentions and actual turnover (Swider\& Zimmerman, 2010). When an individual is exhausted, one's personal resources are spent and as a consequence, employees engage in withdrawal and avoiding coping strategies to protect themselves from further damages to their health (Halbesleben, 2006). Consequently, time given to carry out a task may results to emotional exhaustion and as such, workload, work pressure and lack of job description can lead to fatigue which may inturn lead to physical ailment. Therefore any employee faced with this trauma tends to perform lower than expected which may also lead to absenteeism and turnover.

\subsection{Employee Performance}

According to Ahmad and Shahzad (2011), obviously, employee performance embodies the entire belief of the employee about their conduct and contributions to the achievement of the organization. Similarly, Anitha, (2014) define employee performance as an indicator of financial or other outcome of the employee that has a direct relationship with the performance of the organisation as well as its accomplishment. There are major factors determining employee performance which include: working atmosphere, leadership, team and co-worker relationship, training and career development, reward programme, guidelines and procedures and workstation wellbeing as well as employee engagement. To this end, this study employed non financial performance measures which are effectiveness, productivity, commitment and work quality. These measures can further be described as an important output in determining employee performance particularly in recent area of human resources.

Consequently, Alagaraja and Shuck (2015) intends to ascertainexisting viewpoints of organizational arrangement and employee engagement in order to comprehend reasons related with enhancing individual performance. Furthermore, Thomas and Feldman, (2010) assumed measures of employee performance as core task performance, which includes in-role performance, safety performance, and creativity, citizenship performance and counterproductive performance which consists of general counterproductive work behaviours, workplace aggression, substance use, tardiness, and absenteeism. Therefore, employee performance brings about firm performance in such a way that successful effort of fulfilled, inspired, and devoted human resources produces innovative ideas for new services and increase quality performance and employee satisfaction directly 
(Sadikoglu\&Zehir, 2010). However, performance from this study context entails employee level of productivity, effectiveness at work and quality of service delivered in line with the accomplishment of organisational set goals and objectives.

\subsection{Theoretical Framework}

For the purpose of this study, conservation resources theory will become the bedrock upon which this study shall rest on. Conservation of resources theory was used in order to increase the personal resources among the workers and to overcome the strain situation when there ishigh of demand in the organization particularly among academic staff and that those employees withadditional task, excess workload and responsibilities are likely to be in stress situation. In view of this, the workload of academic staff in recent time is becoming more tedious and complex in Nigerian tertiary institution which makes this theory the most relevant theory to underpin this study. Therefore, the theoretical framework established nexus between emotional exhaustion and employee performance.

\section{METHODOLOGY}

The study was conducted in Ekiti State. Survey research design was employed through the use of structured questionnaire to gather necessary information needed for the study. The study population covered only the academic staff of tertiary institutions in Ekiti State which is two thousand six hundred and nine $(2,609)$ academic staff in total as revealed by the personnel office record of each institution in Ekiti State.Eight tertiary institutions in Ekiti State are conveniently selected which are: Ekiti State University, Ado-Ekiti, Federal University, Oye-Ekiti, AfeBabalola University, Ado-Ekiti, Federal Polytechnic, Ado-Ekiti, Crown Polytechnic, odo, College of Education, IkereEkiti, College of Health Science and Technology, IjeroEkiti and EKSUTH School of Nursing, Ado-Ekiti. Only academic staff constituted the target respondents due to their workload and complexity compared to other category of staff in the tertiary institutions. Therefore, one thousand two hundred and fourteen(1214) respondents will be sampled using Yamane sampling model to determine the sample size for each tertiary institution.Emotional exhaustion was measured by time constraint, physical ailment and work pressure while descriptive and inferential statistic was employed. Descriptive statistics included the use of frequency table to analysis the respondents while multiple regression analysis which is inferential statistics was used to test the hypothesis.

\section{DISCUSSION AND FINDINGS}

\subsection{Presentation of Respondents' Demographic Data}

From the demographic distribution, one thousand two hundred and fourteen (1214) respondents were sampled, 911 questionnaires were filled and returned which represented approximately $75 \%$ response rate which thus implied that the response rate to the information needed for this study is adequate enough for data analysis. The data gotten from the retrieved questionnaires were employed for this study.

Table1: Respondents Demographic Distribution

\begin{tabular}{lcc}
\hline Variables & Frequency & Percent \\
\hline Gender & & \\
Male & 591 & 64.9 \\
Female & 320 & 35.1 \\
Total & $\mathbf{9 1 1}$ & $\mathbf{1 0 0 . 0}$ \\
Marital Status & & \\
Single & 323 & 35.5 \\
Married & 573 & 62.9 \\
Divorced & 15 & 1.6 \\
Total & $\mathbf{9 1 1}$ & $\mathbf{1 0 0 . 0}$ \\
Academic Qualification & & \\
HND/B.Sc & 110 & 12.1 \\
MBA/M.Sc & 501 & 55.0 \\
Ph.D & 300 & 32.9 \\
Total & $\mathbf{9 1 1}$ & $\mathbf{1 0 0 . 0}$ \\
Year of Experience & &
\end{tabular}


$1-5$

6-10

$11-15$

16 Above

Total
178

143

911
27.1

37.7

19.5

15.7

100.0

Source: Field Survey, (2019)

From the gender distribution, it was shown that $591(64.9 \%)$ of the total respondents were male while $320(35.1 \%)$ were female. The summary of the response gathered here shows male staff is more than the female staff. Considering the staff's marital status, $323(35.5 \%)$ of the total respondents were single, $573(62.9 \%)$ were married while only $15(1.6 \%)$ of the total respondents were divorced. The summary of the response gathered here shows that the larger populations of respondents are married. As depicted on the academic background distribution, it was shown that 101 (12.1\%) of the respondents are first degree holders, $501(55.0 \%)$ of the respondents are second degree holders while 300 (32.9\%) of the respondents are third degree holders thus implied that most of the respondents surveyed are second degree holders. Finally, It was also shown that 247 (27.1\%) of the respondents were within the range of 1-5years of experience, $343(37.7 \%)$ were within the range of 6-10years of experience, $178(19.5 \%)$ respondents were between 11-15years of experience, 143 (15.7\%) respondents were between 16 years of experience and above. This indicated that majority of the respondents were within the range of 6-10 years of experience.

\subsection{Discussion of Result}

Emotional exhaustion will not significantly affect employee performance among Academic Staff of Tertiary Institutions in Ekiti State, Nigeria.

Table 2: Regression Results of Emotional Exhaustion on Employee Performance

\begin{tabular}{|c|c|c|r|r|r|r|r|}
\hline \multirow{2}{*}{ Model } & $\mathbf{R}$ & $\mathbf{R}^{\mathbf{2}}$ & Adj R & B & Std Error & T value & $\begin{array}{c}\text { P } \\
\text { Value }\end{array}$ \\
\cline { 2 - 8 } & 0.550 & 0.302 & 0.269 & & & & \\
\hline Time Constraint & & & & .506 & .146 & 3.454 & .001 \\
\hline Physical Ailment & & & & .399 & .224 & 2.776 & .040 \\
\hline Work Pressure & & & & -.368 & .192 & -2.910 & .005 \\
\hline Constant & & & & 1.500 & .694 & 2.162 & .034 \\
\hline F-Cal* & 9.230 & \multicolumn{7}{|c}{} \\
\hline F- Tab & 1.645 & \multicolumn{7}{|c|}{} \\
\hline
\end{tabular}

\section{Source: Field Survey, (2019)}

To test this hypothesis, three variables were used to proxy emotional exhaustion (Time Constraint, Physical Ailment and Work Pressure) From Table 2, the R (Regression Coefficient) gives a positive value of 0.550 ; this indicated that emotional exhaustion has a strong effect on employee performance. The $\mathrm{R}^{2}$ is a portion of the total variation in the dependent variable that is explained by the variation in the independent variables. From the results obtained, $\mathrm{R}^{2}$ is equal to 0.302 , this implies that time constraint, physical ailment and work pressure brought about $30.2 \%$ variance in employee performance among tertiary institutions in Ekiti State, this is further proven by the adjusted $\mathrm{R}^{2}$ that shows the goodness of fit of the model which gives a value of 0.269 , implying that when all errors are corrected and adjustments are made the model can only account for $26.9 \%$ of emotional exhaustion in the surveyed tertiary institutions. However, emotional exhaustion variables (time constraint, physical ailment and work pressure) were subjected to multiple regression analysis as shown in Table 2.

From the Table 2, the unstandardized $\beta$ co-efficient of time constraint gives a positive value of 0.506 with $t=3.454$ and $(\mathrm{P}=0.001$ $<0.05)$. This result showed that time constraint has a positive significant effect on employee performance, therefore, it was found significant. This means that respondents' reason for employee performance is strongly and positively influenced by emotional exhaustion as shown in Table 2. However, the higher the T-value, the better the result and the positivity of the result showed that tertiary institution staff feel somehow exhausted and depressed most time due to the time constraint given to carry out their task. This in accordance to the study of Akande, Patrick and Linus (2018) who found that physical fatigue affects employees' commitment in Nigeria.

The unstandardized $\beta$ co-efficient of physical ailment gives a negative value of -0.399 with $\mathrm{t}=-2.776$ and $(\mathrm{P}=0.040<0.05)$. This result showed that physical ailment has a negative and significant effect on employee performance, therefore, it was found significant. This means that respondents' reason for employee performance is influenced by emotional exhaustion as shown in 
Table 2. However, the higher the T-value, the better the result and the negative of the result showed that persistence of stress for lengthy period makes staff of tertiary institutions suffer physical ailment and reduces the performance of academic staff. This in accordance to the study of Bavani, Muhammad and Manaf (2016), the study examined the influence of dimensions of job burnout on employees' commitment in Malaysia. The results showed that emotional exhaustion and depersonalization were significantly negatively associates with job commitment

From Table 2, the unstandardized $\beta$ co-efficient of work pressure gives a negative value of -0.368 with $\mathrm{t}=-2.910$ and $(\mathrm{P}=0.005<$ 0.05). This result showed that work pressure has a negative and significant effect on employee performance therefore, it was found significant. This means that respondents' reason for employee performance is influenced by work pressure. However, the higher the T-value, the better the result and the negativity of the result showed that tertiary institution work pressure determine the level of staff tiredness and fatigue on the job which results to poor academic performance of academic staff in Ekiti State. This in accordance to the study of Nafees, Kanwal and Shoaib (2015) who found that exhaustion and disengagement had a moderate negative impact on in-role performance. This study provides useful insights to the top management on reducing burnout among employees in Lahore.

The multiple regression equation of the model is:

Employee Performance $=1.500+0.506 \mathrm{Tct}-0.399$ Pam $-0.368 \mathrm{Wps}$

\subsection{Test for Significance}

The F-test is used to test the overall significance of a model by comparing the F calculated with the F tabulated, the comparison is done on Table 2. The table shows that the calculated value of $F$ distribution gives a value greater than the F tabulated. Hence, we accept alternate hypothesis and reject null hypothesis. This implies that emotional exhaustion will significantly affect employee performance among academic staff of tertiary institutions in Ekiti State.

\section{CONCLUSION}

This study examined the effect of emotional exhaustion on employee performance particularly among staff of Tertiary Institutions in Ekiti State. As revealed from the study findings, it was found that emotional exhaustion has significant effect on employee performance though physical ailment and work pressure has negative effect on employee performance as revealed by the findings thus implied that increase in physical ailment and work pressure will reduce employee performance and that time constraint positively affect employee performance of academic staff in Ekiti State. Therefore, the study accepted alternate hypotheses and rejected otherwise thus concluded that emotional exhaustion is positively and significantly related to employee performance particularly among staff of Tertiary Institutions in Ekiti State.

\subsection{RECOMMENDATIONS}

Emotional measures were found significant on employee's performance except work pressure. Therefore, management of tertiary institutions in Ekiti State should ensure time assigned to responsibilities is fair enough to avoid unnecessary stress in order to enhance employee effectiveness and achieve a better performance. Similarly, attention should be given to employee working hours and workloads that can result to physical ailment or increase absenteeism among academic staff. It was revealed that pressure has a negative effect on performance thus it is recommended that effective strategy should be put in place to help employees cope with work pressure and develop their level of confidence on the job.

\subsection{Suggestion for Further Studies}

This study targeted academic staff in Ekiti State Tertiary Institutions. This study can be replicated in other sector like telecommunication or banking sector where employees are faced with high pressure to meet up with targets. Therefore, further studies can be extended towards these areas highlighted.

\section{REFERENCES}

1. Ahmad, S., \&Shahzad, K. (2011). HRM and employee performance: A case of university teachers of Azad Jammu and Kashmir (AJK) in Pakistan. African Journal of Business Management, 5(13), 5249 . 
2. Akande, B. B., Ologbenla, P., \& Linus, I. O. (2018). Employee's job burnout, worker's satisfaction and commitment in Nigerian Banking Industry: A study of Access Bank Plc. International Journal of Business and Management Review, 6(2), 45- 54.

3. Akhigbe, O. J., \& Gail, O. J. (2017). Job burnout and organizational cynicism among employees in Nigerian Banks. European Scientific Journal, 13(22), 125-140.

4. Alagaraja, M., \& Shuck, B. (2015). Exploring Organizational Alignment-Employee Engagement Linkages and Impact on Individual Performance a Conceptual Model. Human Resource Development Review, 1534484314549455.

5. Anitha, J. (2014). Determinants of employee engagement and their impact on employee performance. International Journal of Productivity and Performance Management, 63(3), 308-323.

6. Basami, A., Chizari, M., \&Abbasi, E. (2013). Investigating relationship between job burnout and organizational commitment among extension workers in Kurdistan Province, Iran.International Journal of Humanities and Social Science Invention, 2(10), 63-67.

7. Bavani, S., Abdullah, M. S., Manaf, A. H. A. (2016).The influence of dimensions of job burnout on employees' commitment: A perspective of Malaysia. Journal of Business and Management Studies, 1(4),169-178.

8. Boonratana, V., \& Gharleghi1, B. (2015). Determinants of the Job Burnout in Public Sector Employees in Malaysia. International Journal of Business and Management, 10(6), 208-216.

9. Cropanzano, R., Rupp, D. E., \& Byrne, Z. S. (2003). The relationship of emotional exhaustion to work attitudes, job performance, and organizational citizenship behaviours. Journal of Applied Psychology, $88,160-169$.

10. Gaines, J., \&Jernier, J. M. (1983). Emotional exhaustion in a high stress environment. Academy of Management Journal, 26, 667-686.

11. Halbesleben, J. R. B. (2006). Sources of social support and burnout: A meta-analytic test of the conservation of resources model. Journal of Applied Psychology, 91(5), 1340-1145.

12. Inuwa, M. (2016). job satisfaction and employee performance: An empirical approach. The University Journal, 1(1), 90-103.

13. Kwag, S. H., \& Kim, M. H. (2009). The study on the effects of organizational members' job Journal of Business and Economics Research, 7(7), 63-78.

14. Maslach, C., \& Jackson, S. E. (1986). Maslach burnout inventory manual. Palo Alto: Consulting Psychologists Press.

15. Maslach, C., \&Leiter, M. P. (1997). The truth about: How organizations cause personal stress and what to do about it. San Francisco: Jossey-Bass.

16. Maslach, C., \& Jackson, S. E. (1981). The measurement of experienced burnout. Journal of Occupational Behaviour, 2, 99-113.

17. Muda, I., Rafiki, A., \&Harahap, M. R., (2014). Factors influencing employees' performance: A study on the Islamic Banks in Indonesia. International Journal of Business and Social Science, $\quad 5(2) .73-80$.

18. Nafees, H. M., Kanwal1, S., \&Shoaib, M (2015). Impact of job burnout on the in-role performance of front-line employees: a case of banks in Lahore. Sciences 'International Lahore, 27(1), 531-535.

19. Ogbulafor, C. (2011). Motivation and job performance of academic staff of state universities in Nigeria: the case of Ibrahim BadamasiBabangida University, Lapai, Niger State. International Journal of Business and Management, 7(14), 142.

20. Oluwafemi, O. J. (2010).Predictors of turnover intention among employees in Nigeria's Oil Industry. Organizations and Markets in Emerging Economies, 2(8), 42-63.

21. Pines, A., \& Aronson, E. (1988). Career burnout causes and cures. London: MacMillan.

22. Roloff, M. E., \& Brown, L. A. (2011). Extra role times, burnout and commitment: The power of promises kept. Business Communication Quarterly, 74(4), 450-474. 
23. Sadikoglu, E., \&Zehir, C. (2010). Investigating the effects of innovation and employee performance on the relationship between total quality management practices and firm performance: An empirical study of Turkish firms. International Journal of Production Economics, 127(1), 13-26.

24. Swider, B. W., \& Zimmerman, R. D. (2010). Born to burnout: A meta-analytic path model personality, job burnout and work outcomes. Journal of Vocational Behaviour, 76(3), 487- 506.

25. Thomas, W. J., \& Feldman, D. C. (2010). Organisational tenure and job performance. Journal of Management, 6(5), 1220-1250.

26. Westman, M., \& Eden, D. (1997). Effects of a respite from work on burnout: Vacation relief and fade- out. Journal of Applied Psychology, 82, 516-27.

27. Yamane, T. (1967). Elementary sampling theory. Englewood Cliffs: Printice hall. 